\title{
Power and responsibility - Integrating a new technology battery into an existing power network
}

\begin{abstract}
Author Robert Graham Blakey MSc, BSc, ACGI, MIET, RCNC.
Synopsis The high energy density of new technology batteries, for example lithium-ion, comes with a downside; potentially extreme short-circuit current. This paper will describe the capability of a demonstrator for a new main battery for a submarine, the consequences of connecting it to the existing DC distribution system, and how the release of stored energy is to be controlled. A complication is that proprietary battery management systems will shut down on excessive current demand, but that behaviour is not consistent with the UPS support function of the battery or with making conventional fault clearance discrimination work in the extended network it serves. An innovative technique to meet the real-life use requirement will be described, giving an energy source with both power and responsibility.
\end{abstract}

Keywords Large battery array, fault current, circuit breaker, distribution network, UPS, safety.

Biography Mr Blakey has had a long career as a Marine Electrical Engineer in the UK Ministry of Defence. Recent roles have been as sponsor for the HV network on the QEC (aircraft carrier) project, Design Authority (Electrical) for in-service submarines, and latterly working on future projects in the Submarine Chief Engineer's department.

\section{Introduction - The task.}

Engineers are familiar with power; volts times amps or force times distance moved per second. Putting environmental considerations aside, there is always a desire for more power - more is better. But as in society, so in engineering power must be used responsibly for a good outcome. Responsibility, for engineering plant, is taken to be doing the job it is designed for, doing it reliably, and not presenting an undue hazard when it does inevitably fail.

The context for this paper is finding a replacement for the main battery in a nuclear-powered submarine, when you are enclosed in a 4000 cubic metre tube with 100 other people and all of the propulsion and life support machinery, you need them all to behave responsibly. How does this requirement apply to the main battery? And can this requirement be met when aiming for a doubling in kilowatt-hours stored?

The basis for the work reported in this paper is a technology demonstrator programme (TDP) to explore the practicability of doubling the energy storage of a submarine main battery. The target application is an existing design so that there is little scope for major changes to the systems or the structure of the vessel. This constraint guides some of the design decisions. A significant output from the TDP will be a safety case, with evidence, to support a pioneering installation on an in-service boat.

\section{The role of the main battery.}

In a conventional submarine, the main battery provides a cycling energy store. It is charged up in as short as possible time by diesel generators, then releases energy for propulsion and platform services over a much longer period. By contrast, the main battery in a nuclear-powered submarine is the ultimate power source, albeit transient, should the nuclear plant stop working. The main battery is in a similar position to the battery in an uninterruptible power supply (UPS), where it stands ready to provide energy on immediate demand.

The subtle difference between a UPS battery and that of the submarine is that the submarine battery supports the vital DC system. This system feeds equipment throughout the boat which are the last line in maintaining propulsion, depth control and life support. As a distributed power system, part of its design is a graded protection scheme with current and time discrimination between the levels of the system. The battery needs to provide high levels of current for a significant time to make this discrimination chain work, to trip circuit breakers or blow fuses in the correct sequence. Figure 1 shows an outline of the vital DC power system. 


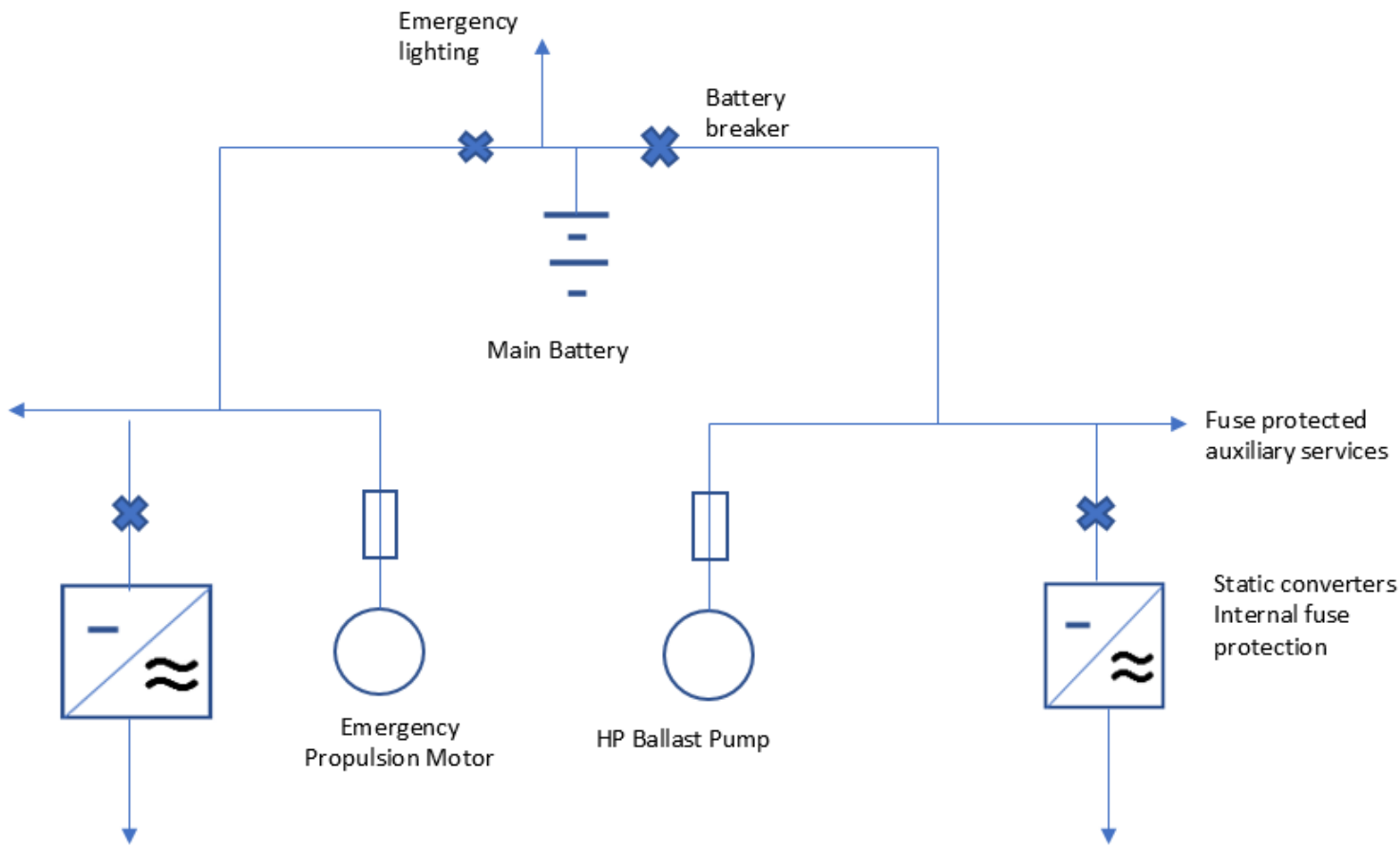

Figure 1. Vital DC power system schematic

\section{Integrating the battery}

The DC system operates at a nominal $250 \mathrm{~V}$, which can be matched by selecting the right number of cells in series. However, the existing flooded lead acid battery (FLA) needs to be charged periodically, which puts an upper limit of $310 \mathrm{~V}$ on the system operating range. The lower limit of $170 \mathrm{~V}$ is determined by the collapse of voltage at the end of a battery deep discharge. An alternative battery technology must operate within this range, and preferably close to the nominal.

The potential discharge current is up to 4000A. In the FLA, supplying this current depresses the output voltage significantly, further increasing the current to feed the constant-power loads.

The FLA needs periodic attention, with regular tasks of measuring acid levels and specific gravity, occasional top up of cells with distilled water and checking of bolted connections between cells. These exposed connections are a touch and short circuit hazard.

The action of charging the battery causes hydrogen, which is flammable at a wide range of concentrations, to be evolved. Sulphuric acid mist is also created. Both these by-products must be removed by the ventilation system.

Physical integration is equally important to electrical integration. The FLA battery weighs 10 s of tonnes and is sited close to the keel of the boat where it provides essential ballast and lowers the centre of gravity, contributing to stability. Weight is good in this application!

The volume available to fit a replacement is fixed to that of the existing battery tank. It is not practicable to make changes to the physical structure of the boat, so the battery tank must contain both a new battery and any control, management or cooling equipment that comes with it. Table 1summarises the integration considerations. 


\begin{tabular}{|c|c|}
\hline Consideration & Performance \\
\hline Nominal load current & 170V - 310V, nominal 255V \\
\hline Voltage range & 8800Ah at 5 hour rate \\
\hline Capacity & Hydrogen (when equalising charge applied) \\
\hline Emissions in normal service & Heavy \\
\hline Weight (comparative) & 20 m ${ }^{3}$ \\
\hline Active volume & Sulphuric acid mist \\
\hline Hazards to personnel & Exposed high current terminals \& links \\
\hline Support Equipment & Acid agitation (air bubbler system) \\
& Deionised water (cell top-up) \\
& Ventilation (high volume when charging) \\
& Hydrometer and electrolyte level detectors \\
\hline
\end{tabular}

$\underline{\text { Table 1. Battery Integration Considerations }}$

\section{A Contender}

What miracle product can meet or improve upon the integration attributes of the FLA battery, and give the doubling of energy storage $\left(\mathrm{kWh} / \mathrm{m}^{3}\right)$ that is the target? One of the new lithium chemistries may come to mind but the solution being proposed is based on a much older chemical couple - Nickel-Zinc (NiZn). Figure 2 gives the chemical cycle.

\begin{tabular}{|c|c|c|c|c|c|c|}
\hline \multicolumn{3}{|c|}{$\begin{array}{l}\text { - Anode Material: } \\
\text { - Electrolyte: } \\
\text { - Cathode Material: }\end{array}$} & \multicolumn{4}{|c|}{$\begin{array}{l}\text { Zinc / Zinc Oxide } \\
\text { Aqueous Potassium Hydroxide } \\
\text { Nickel-Oxyhydroxide / Nickel-Hydroxide }\end{array}$} \\
\hline Anode: & $\mathrm{Zn}$ & $+2 \mathrm{OH}^{-}$ & & $\frac{\text { discharge }}{\stackrel{\text { charge }}{\text { charg }}}$ & $\mathrm{Zn}(\mathrm{OH})_{2}+2 \mathrm{e}^{-}$ & $E^{\circ}=-1.24 \mathrm{~V}$ \\
\hline Cathode: & \multicolumn{3}{|c|}{$2 \mathrm{NiOOH}+2 \mathrm{H}_{2} \mathrm{O}+2 \mathrm{e}^{-}$} & $\underset{\text { charge }}{\stackrel{\text { discharge }}{\rightleftharpoons}}$ & $2 \mathrm{Ni}(\mathrm{OH})_{2}+2 \mathrm{OH}^{-}$ & $\mathrm{E}^{\circ}=0.49 \mathrm{~V}$ \\
\hline
\end{tabular}

- Nominal voltage of 1.73 volts

- Discharge reaction is exothermic

Figure 2. Nickel-Zinc cycle

The nickel-zinc couple was patented by Thomas Edison in 1901, but was not commercially successful in the intermediate century due to problems keeping the zinc anode stable under repeated charge-discharge cycles. In the past few years, researchers have changed the details of the electrolyte formulation to overcome the historic deficiencies.

NiZn was identified as a front runner for the main battery application in a technology survey report (unpublished) which looked at and scored a wide range of chemistries, including variations of lead-acid, nickelsulphur, and alternative lithium-ion formulations. Figure 3 has been taken from an open website (www.zincfive.com) and shows comparative results similar to those identified in the technology search. 


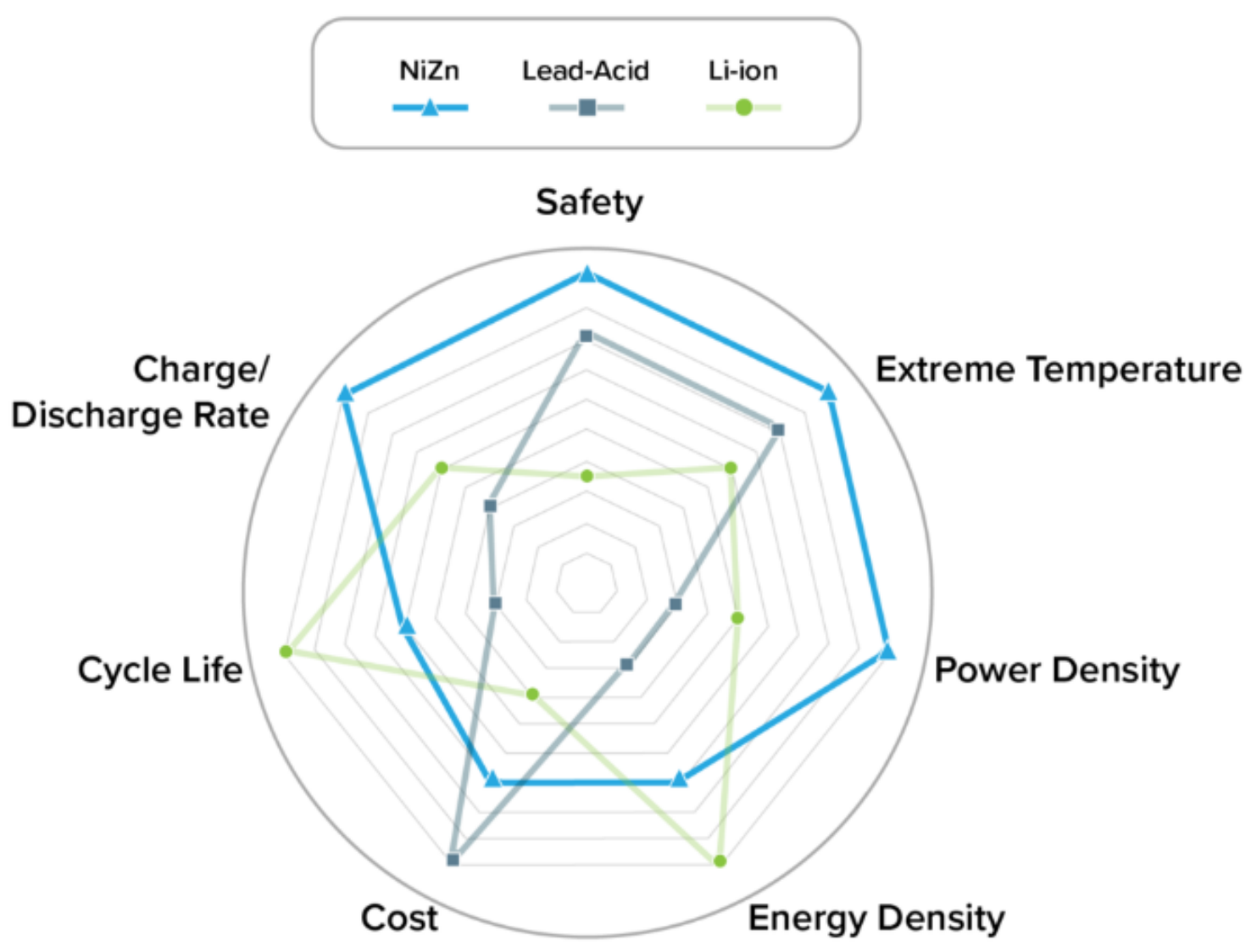

Figure 3 Spider-graph comparing Li-ion, Lead-Acid and NiZn Attributes

Note: radially outward is 'better'.

The technology search was followed by a world-wide call for interest to manufacturers or system integrators, to contract for a project definition study that would define the TDP work. Two parallel competing studies were undertaken, one offering a solution on a proprietary lithium cell and the other using nickel-zinc chemistry. Both cell types were of similar $\sim 100 \mathrm{Ah}$ rating. NiZn was chosen for the TDP as it offered easier physical integration with the vessel and a lower risk of being able to make a satisfactory safety case.

As a result, the basic cell that is being used for this development has a capacity of $120 \mathrm{Ah}$, has a prismatic construction for denser packing, and the potassium hydroxide aqueous electrolyte is absorbed into the separator between the cathode and anode plates. The construction is similar to that of a valve-regulated lead acid battery (VRLA), and like the VRLA, the cell does not gas when charged (or discharged). Table 2 summarises the cell attributes, and Figure 4 is a partial cut-away view.

- Prismatic single cell

- Rated capacity of $120 \mathrm{Ah}$ at 10 hour rate

- Very High Power and Energy Density $\sim 66 \mathrm{Wh} / \mathrm{kg}, 136 \mathrm{Wh} /$ litre

- Flat Ah capacity available vs. discharge rate

- Very good charge acceptance - endothermic too

- Recyclable - all zinc, copper and nickel can be re-captured

- Aqueous chemistry (potassium hydroxide electrolyte)

- Maintenance-free (no top-up or refill required)

- 'Starved' electrolyte -no free liquid

Table 2. NiZn cell attributes 


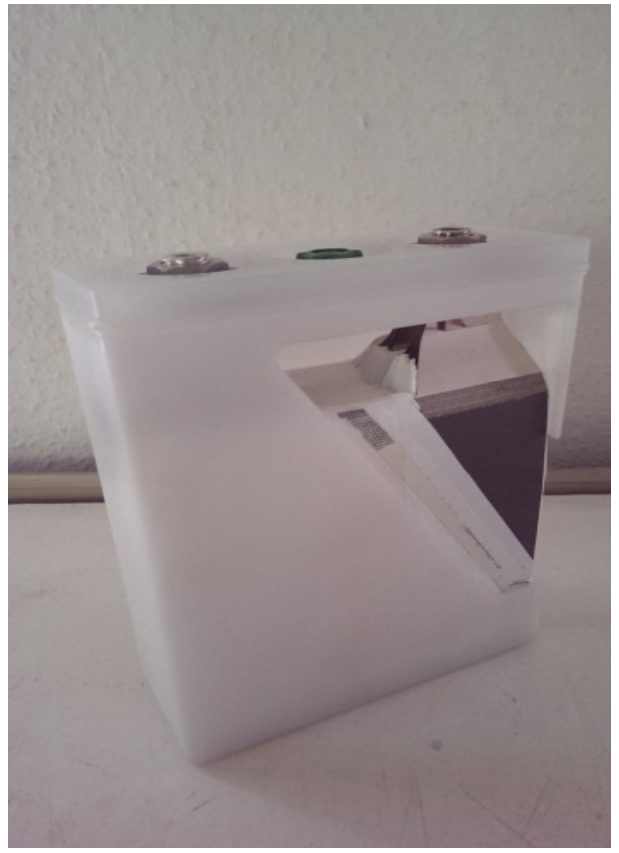

Figure 4. Cut-away view of NiZn cell

To construct the complete battery, 138 cells will be connected in series to form a $250 \mathrm{~V}, 120 \mathrm{Ah}$ module $30 \mathrm{kWh}$ in a volume of $0.22 \mathrm{~m}^{3}$ and weight of comparable with the FLA cells. 133 of these modules are then connected in parallel to form a $16000 \mathrm{Ah}, 4 \mathrm{MWh}$ energy store. This is double the capability of the currently fitted FLA battery but will fit into the same battery tank. The strings of cells do not need any voltage sharing arrangements, nor do the modules need any measures to share the load or charging currents.

The array of modules do not require an active battery management system, in contrast to other high energy systems based on lithium-ion. The overhead (in volume) of the battery management equipment helps make lithium-ion unattractive for this application. Table 3 summarises how this potential new neighbour measures up in terms of power and responsibility.

\begin{tabular}{|l|l|}
\hline \multicolumn{1}{|c|}{ Consideration } & \multicolumn{1}{c|}{ Performance } \\
\hline Nominal load current & $>4000 \mathrm{~A}$ \\
\hline Voltage range & $180 \mathrm{~V}-262 \mathrm{~V}$, nominal 250V \\
\hline Capacity & $16000 \mathrm{Ah}$ \\
\hline Emissions in normal service & None \\
\hline Weight (comparative) & Almost as heavy \\
\hline Active volume & $29 \mathrm{~m}^{3}$ \\
\hline Hazards to personnel & None: no airborne emissions, touch-safe connections. \\
\hline Support Equipment & Remote monitoring system (laptop size) \\
\hline
\end{tabular}

Table 3. NiZn Integration

\section{A good new neighbour?}

The principal improvements over the FLA are obviously stored energy and maintenance-free operation. There is no gas emission over the charge-discharge cycle, and the full capacity of the battery can be used. The links from the sealed modules are low current (30 amps), using polarised connectors, so the touch hazard to crew or installers is removed. Evaluation of the cells has been summarised as 'boring' - they do what they are supposed to, and do not give any surprises when abused. Short circuiting of a small group of cells gives a $150^{\circ} \mathrm{C}$ temperature rise and the venting of steam from the electrolyte, but there is no disruption of the cells or thermal runaway. An internal short circuit created by a 'nail' penetration gives the same unspectacular result (Figure 5). 

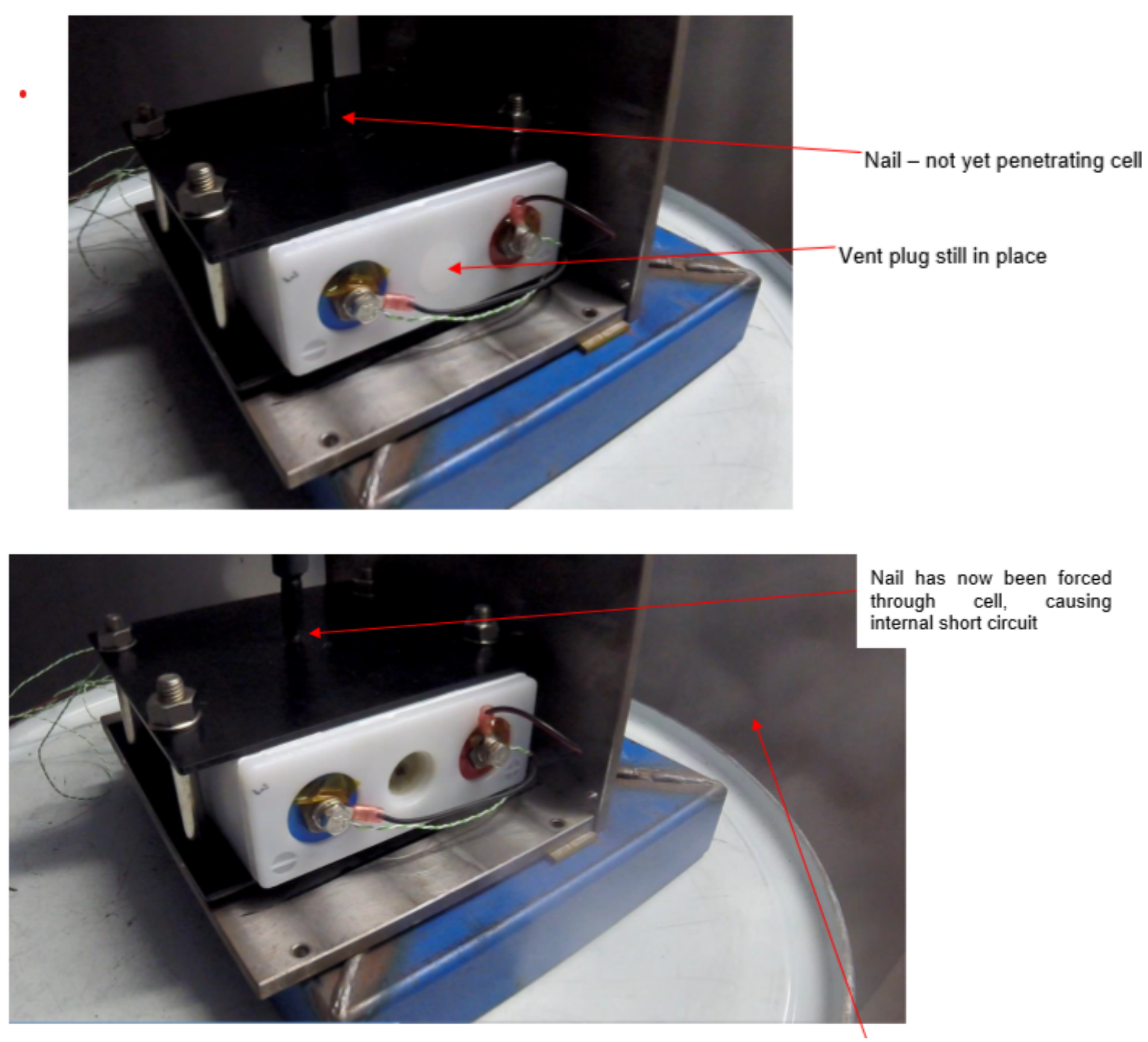

Nail has now been forced through cell, causing internal short circuit

\section{Vapourised electrolyte (water/KOH), which condenses to non-flammable liquid upon contact with surfaces (worst case emissions shown)}

Figure 5 Before-and-after view of 'nail' test.

Note: Vent plug has been ejected by internal pressure, but with no smoke or flame.

A further operational difference from FLA is the reduced voltage range from fully charged to fully discharged (illustrated in Figure 6). There is no limit on recharge rate, as the chemical process during charge is endothermic: the cells tend to cool when being charged. The rated discharge current $(\mathrm{C} / 4$, where $\mathrm{C}$ is the numeric of the cell's ampere-hour capacity) is sufficiently low that temperature rise is calculated to be minimal (measured at approximately $5^{\circ} \mathrm{C}$ ). 


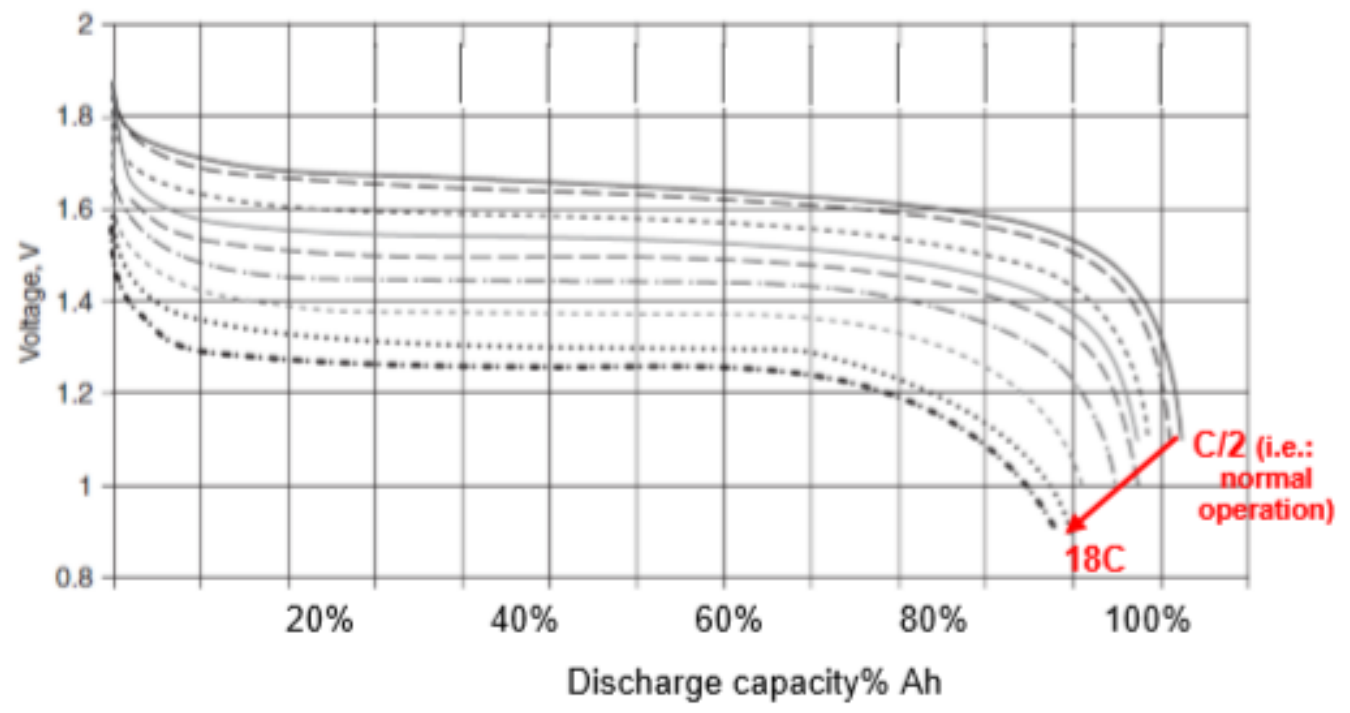

Figure 6 Voltage-discharge map for NiZn cell.

Note: Curves are various current demands

One characteristic does pose a question though. In common with other high power or high energy chemistries, NiZn has a low impedance and a high short circuit current. Expressed as a multiple of the amperehour capacity of the cell, C, 40C is representative. This means that for the 16000Ah array that the prospective short circuit current is more than half-a-million amps. The rise time is measured in microseconds, and the duration over one minute. This capability needs to be reined in, but integration into an existing power system presents complications.

DC Machine and Syste m Protection

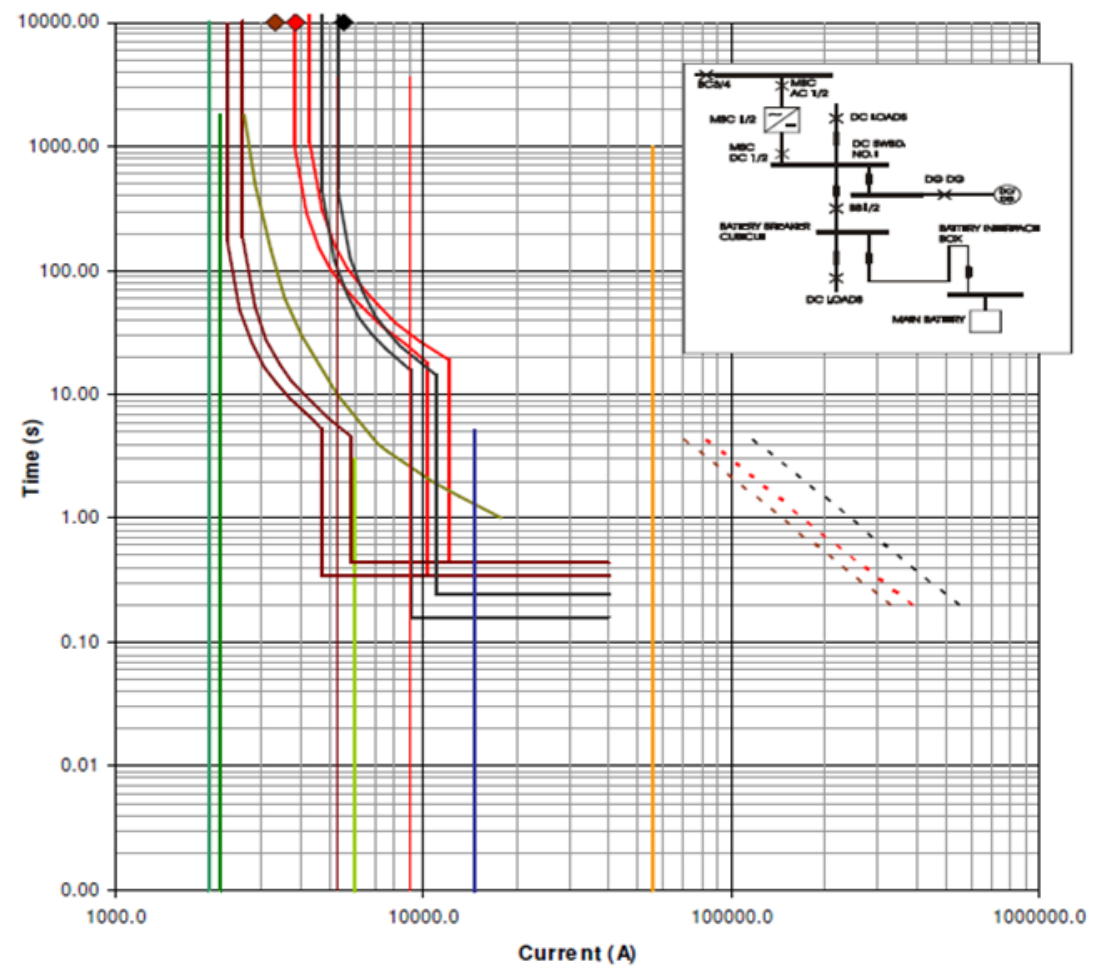

Figure 7. DC circuit breaker protection characteristics

Note: Vertical line at 55kA is the FLA short circuit capability. 


\section{Overload/short circuit current - some, but not too much.}

The existing DC distribution system puts legitimate over-current demands on the battery. Load steps from the static converters can give high rates-of-change of current, and inrush current on converter start can exceed three times the nominal load current of 4000A for a few milliseconds. The design of the protection hierarchy needs the battery to provide more than 40kA for up to 500 milliseconds; Figure 7 shows the time-current characteristics of the protection relays on circuit breakers connected on the system.

At first sight, there is no need for an upper limit on the current that the battery can provide. The FLA battery is assumed to supply 55kA at its terminals, but this will be attenuated by conductor resistance going further out over the DC system. In practice, there is little margin for allowing an increase in short circuit capability. The circuit breakers have an upper limit on the short circuit current that they are qualified to interrupt and the fuses which feed lower-rated consumers are tested and certified for operation with a source with a prospective current of $40 \mathrm{kA}$.

Another consideration is what happens if there is a short circuit between the battery terminals and the battery circuit breaker cubicle. With the FLA, this area is intended as a fault-free zone but is not protected, and incidents have occurred in other installations. A protection scheme for the new battery that also covers this zone would be a big bonus.

\section{Options for achieving short circuit current limitation.} deficiencies.

There are a number of possibilities for controlling the potential short circuit current but most have major

\section{High-speed circuit breakers}

One version of these devices works by diverting the current into a solid-state device, then opening mechanical contacts in 100s of microseconds, then switching off the solid-state bypass. The problem with this proposal is that the device rating is nowhere near the $>4 \mathrm{kA}$ load current specification, and interruption in less than 1 millisecond does not provide the current for sufficient time for the discrimination chain. Conclusion - not viable

Solid-state circuit breakers

A solid-state circuit breaker could be based on an IGBT or an integrated gate-controlled thyristor (IGCT). This would achieve a switching time of 10 s of microseconds but could not supply the sustained but limited current that the discrimination chain requires. Another problem with a solid-state switch is the standing losses when operating - a power transistor or thyristor will have a forward voltage drop of around 2 volts. The losses at $4 \mathrm{kA}$ would be $8 \mathrm{~kW}$, demanding a forced cooling system for the switch. Shunting the solid-state device with a mechanical switch to reduce losses brings back the problem of operating time, probably 10-15 millisecond, by which time the current may have risen to $100 \mathrm{~s}$ of $\mathrm{kA}$. Additionally, the solid-state switch must be continuously rated for the let-through current $(\sim 50 \mathrm{kA})$, and a current limiting feature has still to be devised. Conclusion - not viable.

\section{Additional impedance (1)}

Resistance could be built in to the battery so that the short circuit current is limited to 50kA. With an internal emf of $250 \mathrm{~V}$, a total resistance of 5 milliohms is needed, but this would incur a voltage drop of $20 \mathrm{~V}$ at the $4 \mathrm{kA}$ discharge rating, and lose $80 \mathrm{~kW}$. This is not tolerable, but if the extra resistor is lumped, it could be switched out in normal operation by a mechanical or solid-state switch. Unfortunately, this switch would have the same drawbacks already described - slow operation or excessive losses and overrating.

Additional impedance (2)

The battery voltage of $250 \mathrm{~V}$ is sufficiently low that power MOSFETs can be used for switching. [A MOSFET switches between a high and low resistance under the influence of a gate potential.] A suitable design for this application would have an on-resistance of 0.1 milliohms; at 4000A the device loss is $1600 \mathrm{~W}$ and voltage drop is only $400 \mathrm{mV}$, which compares very favourably with the $8 \mathrm{~kW}$ loss and $2 \mathrm{v}$ drop in a central IGBT or thyristor switch. However, implementing this design using available devices would need hundreds of switches in hard 
parallel and still require forced cooling. This is a high-risk development, but what if each module had its own MOSFET switch? The battery array load current of $4 \mathrm{kA}$ corresponds to a module current of $30 \mathrm{~A}$. This is sufficiently low that commercially available devices can be contemplated.

By subdividing the battery, a practicable high-speed switch solution can be constructed, but this does not provide the current for the discrimination chain. At 40kA total, each module needs to provide300A for up to 500 milliseconds, whereas each module could give almost 5000A (40C), so this has to be moderated.

One solution is to connect into the circuit a current-limiting resistor when the load on the module exceeds a generous overload figure (for example, $3 \mathrm{xFLC}$ ). The resistor is short-term rated (the current feeding the external fault is only supplied for 500 milliseconds) so the excess energy heats the bulk of the resistor; the energy then dissipates to the environment after the fault event is over. This duty is beyond the capability of catalogue components like metal-clad resistors which are designed for continuous operation, so a bespoke design is needed. The secret of success is ensuring that the resistor has sufficient effective mass; about $1 \mathrm{~kg}$ is needed. It is formed into a bobbin $90 \mathrm{~mm}$ diameter and $50 \mathrm{~mm}$ high - think large teacup.

Using a MOSFET switch with a current-limiting resistor achieves a low solid-state switch voltage drop and conduction loss, and ultra-fast current control, but does not give module isolation or define what happens beyond the 500 millisecond duty period. For this, the current path includes a single-pole contactor or relay and a fuse. These are selected for a let-through current of $>300 \mathrm{~A}$; the relay can interrupt this at the expiry of the 500 milliseconds should the external fault persist. The fuse forms the ultimate backstop for relay fail-to-open, or for an internal fault. Figure 8 summarises this arrangement.

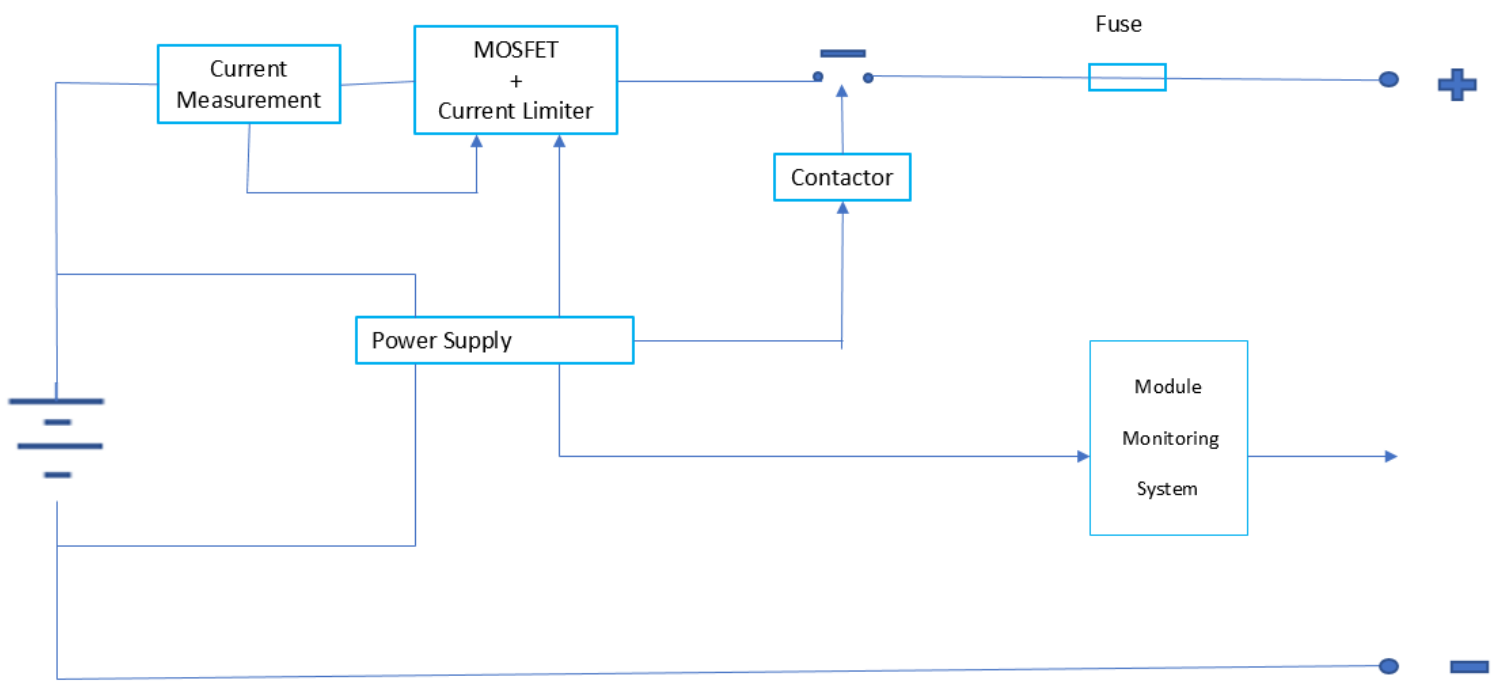

Figure 8. Module current limiting schematic

\section{Conclusion}

A battery technology is available which meets all the operational and environmental constraints of use in an existing design manned submersible, which gives twice the energy storage of traditional FLA batteries, and which is not lithium-ion. This is thought to be a world first. The remaining hazard of excessive fault current, inherent in all high-power batteries, is mitigated without recourse to development of solid-state circuit breakers. By subdividing the capacity into a large number of parallel strings, the potential fault current of $>0.5 \mathrm{MA}$ can be controlled by low-rated, existing technology. The end result - power and responsibility.

Acknowledgements This paper is based on work contracted by the Ministry of Defence with Enersys and PMB Defence Engineering. Any assessments and conclusions expressed are those of the author, and not necessarily of the Ministry of Defence or the companies. Security guidelines and commercial sensitivities have been respected in compiling this paper which has regrettably reduced the technical detail published. 


\section{Bibliography}

Potter and Lichte: Nickel-Zinc Battery Evaluation at Crane. Internet open source, https//ndiastorage.blob.core.usgovcloudapi.net/ndia/2017/power/potter19503pdf

Rhodri W Evans et al: Development of Nickel-Zinc Technology for Military and Civilian Energy Storage Applications. Proceedings, $47^{\text {th }}$ Power Sources Conference, June 14, 2016.

ZincFive website www.ZincFive.com

ZAF Energy Systems website https://zafsys.com

ABB Press Release Messe Hanover,1 April 2019 https://new.abb.com/news/detail/18527/abb-reinvents-thecircuit-breaker-breakthrough-digital-technology-for-renewables-and-next-gen-power-grids

\section{Appendix: Relationship to other technology developments}

\section{Technology Readiness.}

The Nickel-Zinc technology is at TRL 7 or 8, depending on the supplier and is not yet a commercial commodity. The most mature application is that by ZincFive for battery back-up for road traffic lights in the US. Here the demand is to keep the lights working and traffic flowing safely at busy junctions in the event of local power outage.

ZAF Energy Systems in the US are marketing 200Ah G31 format batteries for commercial vehicles, primarily for 'hotel' services and cargo refrigeration at stop-overs. This allows them to meet local anti-idling regulations.

There are comparable applications in the commercial marine sector; leisure batteries for pleasure craft would give twice the energy storage in the same volume as the usual VRLA batteries, for instance. Use for electric propulsion (ferries, for instance) still needs demonstration of load cycle life in the application, and of the ability to charge rapidly at terminals.

\section{Why not mainstream?}

The mass market application for new technology is electric vehicles where Li-ion is seen as the route to high energy density and low weight. The quid pro quo is engineering in safety and high development and purchase costs. The niche application which is the subject of this paper cannot justify this level of expenditure. Despite the investment for vehicle battery technology, a lithium-based system which is notably less hazardous than the current products has not emerged on the commercial market. This shortcoming justifies the selection of a battery technology which is inherently safer than its rivals.

\section{Solid State Breakers}

At the time of writing, ABB have announced a new generation of solid state DC circuit breaker for commercial release in 2020. The press notice gives little information beyond the use of IGCTs with a one Volt forward voltage drop for higher efficiency, and 100 times faster interruption than a mechanical circuit breaker, giving a low arc-flash hazard. An accompanying film suggests a nominal rating of $2000 \mathrm{~A}, 1000 \mathrm{~V}$. There is no statement of interruption capability or prospective fault current.

For the technology demonstrator which is the subject of this paper, the project has discounted the use of solid state circuit breakers, either all-solid state or hybrid, for the following reasons.

- Availability to purchase. There is no known product which will handle the load and overload currents placed on the battery. Solid state breakers in parallel would be a new development in itself. 
- Volume. There is no free volume on the target platform to install additional circuit breakers. The existing units, or their volume, must be used.

- Safety Case. The control of solid state breakers is advertised as through software - this gives a new dimension of complexity to making a safety case for the battery installation.

- Operation with existing equipment. Integrating a high speed breaker into the distribution system would need wholesale changes to the protection hierarchy. Several consumers are protected by fuses, which by their nature need highly excess current for milliseconds to interrupt. These fuses would have to be changed to solid state protection, another new development beyond the simple scope of this project. 